Xin, Y., Davies, A., McCombie, L., Briggs, A., Messow, C.-M., Grieve, E., Leslie, W.S., Taylor, R. and Lean, M.E.J. (2019) Type 2 diabetes remission: economic evaluation of the DiRECT/Counterweight-Plus weight management programme within a primary care randomized controlled trial. Diabetic Medicine, 36(8), pp. 1003-1012.

There may be differences between this version and the published version. You are advised to consult the publisher's version if you wish to cite from it.

This is the peer reviewed version of the following article Xin, Y., Davies, A., McCombie, L., Briggs, A., Messow, C.-M., Grieve, E., Leslie, W.S., Taylor, R. and Lean, M.E.J. (2019) Type 2 diabetes remission: economic evaluation of the DiRECT/Counterweight-Plus weight management programme within a primary care randomized controlled trial. Diabetic Medicine, 36(8), pp. 1003-1012, which has been published in final form at http://dx.doi.org/10.1111/dme.13981. This article may be used for non-commercial purposes in accordance with Wiley Terms and Conditions for Self-Archiving.

http://eprints.gla.ac.uk/185885/

Deposited on: 18 July 2019

Enlighten - Research publications by members of the University of Glasgow http://eprints.gla.ac.uk 
Diabetic Medicine (3000 words full text, 30 references, 250 abstract)

\title{
Type 2 diabetes remission: economic evaluation of the DiRECT/Counterweight-Plus weight management programme within a primary care randomised controlled trial
}

\author{
A short running title (75 characters): \\ Cost-effectiveness of DiRECT weight management programme
}

\section{Author names}

Yiqiao Xin ${ }^{1}$, Andrew Davies ${ }^{1}$, Louise McCombie ${ }^{2}$, Andrew Briggs ${ }^{1}$, C. -Martina Messow ${ }^{3}$, Eleanor Grieve ${ }^{1}$, Wilma S Leslie ${ }^{2}$, Roy Taylor ${ }^{4}$, Michael EJ Lean²

\section{Affiliations}

1 Health Economics and Health Technology Assessment (HEHTA), Institute of Health and Wellbeing, University of Glasgow, Glasgow G12 8RZ, UK.

2 Human Nutrition, School of Medicine, Dentistry and Nursing, College of Medical, Veterinary \& Life Sciences, University of Glasgow, Glasgow G31 2ER, UK

3 Robertson Centre for Biostatistics, University of Glasgow, Glasgow, G12 8QQ, UK

4 Newcastle Magnetic Resonance Centre, Institute of Cellular Medicine, Newcastle

University, Campus for Ageing \& Vitality, Newcastle upon Tyne NE4 5PL, UK

Trial Registration details: Current Controlled Trials ISRCTN03267836. Date of Registration 20/12/2013

\section{Corresponding author}

Professor Michael Lean mike.lean@glasgow.ac.uk

Telephone: (+44) (0) 1412018604

Human Nutrition, School of Medicine, Dentistry and Nursing, College of Medical, Veterinary and Life Sciences, University of Glasgow. Address: Level 2, New Lister Building, Glasgow Royal Infirmary, 8-16 Alexandra Parade, Glasgow. G31 2ER. 
Manuscript word count: 3289

2 Abstract word count: 245

3

4

6

7

\section{Conflict of Interest disclosures:}

MEJL reports personal fees from Counterweight Ltd, paid to the University of Glasgow for medical advisory consultancy, and advisory board, consultancy and speaking fees from Novo Nordisk, Novartis, Astra Zenica, Eli Lilly, all outside the submitted work. AB reports personal fees for consultancy from Novo Nordisk, Bristol-Myers Squibb, and GSK, outside the submitted work. All other authors declare no competing interests.

\section{Novelty statement (bulleted, maximum 100 words):}

What is already known?

- Diabetes and its complications accounts for approximately $10 \%$ of health care budgets worldwide.

- Counterweight-Plus weight management programme in DiRECT achieved $46 \%$ remissions of Type 2 diabetes and improved cardiovascular risk factors at one year

What this study has found?

- One-year incremental cost for the intervention group was estimated at $£ 982(95 \% \mathrm{Cl}$ $£ 732, £ 1,258$ ) per participant compared to the control arm.

- Providing the DiRECT/Counterweight-Plus intervention in primary care incurs a cost (£2,359 per one-year diabetes remission) below the average annual direct cost of managing a person with Type 2 diabetes (including complications), and has the potential for long-term cost effectiveness

What are the clinical implications of the study?

- Providing a reasonable proportion of remissions can be maintained for a period of time, with multiple medical gains expected, as well as immediate social benefits, there is a case for shifting resources within diabetes care budgets to offer support for people with diabetes to attempt remission as early as possible after diagnosis. 
1 DiRECT is funded by Diabetes UK as a Strategic Research Initiative (award number

2 13/0004691), with support in kind (Counterweight-Plus formula diet sachets) provided by

3 Cambridge Weight Plan. This economic analysis was funded by a separate Project Grant

4 from Diabetes UK (award number 17/0005695). The funders had no role in the study design,

5 conduct, analysis, or reporting.

6

\section{Acknowledgements}

8 We thank the NHS Primary Care Research Network and North East Commissioning Support

9 for their support and valuable input to the DiRECT study recruitment. We thank Maureen

10 McNee, Elaine Butler, Josephine Cooney, Sara-Jane Duffus, and Philip Stewart from the

11 University of Glasgow (Glasgow, UK) for providing technical assistance; Helen Pilkington

12 from the Newcastle upon Tyne Hospitals NHS Foundation Trust (Newcastle upon Tyne, UK)

13 for providing research nurse support; and Sarah Weeden and Sarah Boyle from the

14 Robertson Centre for Biostatistics (University of Glasgow) for project and data management.

15 We are grateful to the general practices, health-care professionals, and volunteers for their 16 participation.

18 Ethical approval

19 The DiRECT was approved by West 3 Ethics Committee in January 2014, with additional approvals by the National Health Service health boards in Scotland and clinical commissioning groups in Tyneside. Informed consent was obtained from all participants. 


\section{Abstract}

2

3 Background: The Counterweight-Plus weight management programme achieved 46\% 4 remissions of type 2 diabetes at one year in the DiRECT trial. We estimated the 5 implementation costs of the Counterweight-Plus programme and its one-year cost6 effectiveness in terms of diabetes remission, compared with usual care, from the UK NHS 7 perspective.

8 Methods: Within-trial total costs included the programme set-up and running cost (practitioner 9 appointment visits, low formula diet sachets, and training), oral anti-diabetes and antihypertensive medications, and healthcare contacts. Total costs were calculated for aggregated resource use for each participant and 95\% confidence intervals were based on 1,000 non-parametric bootstrap iterations.

Findings: One-year programme cost under trial conditions was estimated at $£ 1,137$ per participant $(95 \% \mathrm{Cl} £ 1,071, £ 1,205)$. The intervention led to a significant cost-saving of $£ 120$ $(95 \% \mathrm{Cl} £ 78, £ 163)$ for the oral anti-diabetes drugs and a $£ 14(95 \% \mathrm{Cl} £ 7.9$, £22) saving for antihypertensive medications compared to the control. Deducting the cost-savings of all healthcare contacts from the intervention cost resulted an incremental cost of $£ 982(95 \% \mathrm{Cl}$ $£ 732, £ 1,258)$. Cost per one-year diabetes remission was $£ 2,359(95 \% \mathrm{Cl} £ 1,668, £ 3,250)$.

Interpretation: Remission of type 2 diabetes within one-year can be achieved at a cost lower than the annual cost of diabetes (including complications). Providing a reasonable proportion of remissions can be maintained for a period of time, with multiple medical gains expected, as well as immediate social benefits, there is a case for shifting resources within diabetes care budgets to offer support for people with type 2 diabetes to attempt remission.

Keywords: Cost effectiveness, Cost-benefit, Type 2 Diabetes, Caloric Restriction, Weight Loss 


\section{Introduction}

2 Approximately one in 12 adults worldwide have type 2 diabetes [1]. Care for people with

3 diabetes accounts for $24 \%$ of total healthcare spending in the USA, with more than half directly

4 attributable to diabetes (approximately USD $\$ 9,600$ per diagnosed person per year) [2]. These

5 figures are expected to rise rapidly with increasing prevalence of type 2 diabetes and the

6 introduction of new more expensive treatment options. Diabetes accounted for approximately

$710 \%$ of the total UK NHS budget ( $£ 8.8$ billion in $2010 / 2011$ ), with $80 \%$ attributed to diabetes

8 complications. This is anticipated to rise to $17 \%$ ( $£ 22$ billion) by 2035 , if traditional approaches

9 to diabetes management continue [3]. Indirect costs (economic output lost), were even greater,

10 at $£ 13$ billion, largely through working years lost (including early mortality), and the burden of

11 informal care required for people with diabetes aged over 70 years. In Germany, annual direct

12 healthcare cost was increased 1.8-fold with diabetes (€3,352 vs $€ 1,849)$, and indirect costs

13 elevated two-fold ( $€ 4,103$ vs $€ 1,981)$ compared to those without diabetes [4].

Type 2 diabetes is being diagnosed younger as populations become more overweight, and expensive complications are much more likely with a younger diagnosis [5]. A US study estimated lifetime medical spending at US\$35,900 for people who were diagnosed with diabetes at age 65 years but US $\$ 124,600$ with diagnosis aged 40 years [6]. This suggests that periods of diabetes remission may be particularly valuable for younger people with diabetes, avoiding enormous expenditure.

Current guidelines for type 2 diabetes management focus heavily on drug treatments to lower blood glucose and counter elevated cardiovascular risks. These management strategies, however, are not aimed at remission of diabetes, which progresses, so morbidity and mortality remain high despite the application of clinical guidelines [7]. Bariatric surgery can consistently convert $60-80 \%$ of people with type 2 diabetes to a non-diabetic state for $2-5$ years, through weight loss $>10-15 \mathrm{~kg}$ [8]. Surgical treatments present their own risks and long-term complications, and reach only $1 \%$ of the eligible population [9], and are less preferred by people [10], so other options are needed. Several studies have found weight loss of this order from non-surgical calorie restriction and structured weight-loss maintenance can normalize hepatic fat, blood glucose and insulin, and may extend life expectancy for people with type 2 diabetes [11-13].

The Diabetes Remission Clinical Trial (DiRECT) assesses the extent to which effective weight management, delivered in the primary care setting, can lead to sustained remission of type 2 diabetes [14,15]. DiRECT is an open-label, cluster-randomised trial in 49 primary care practices, which represented the characteristics of people with diabetes and poorer social settings where type 2 diabetes is most frequent in Scotland and the Tyneside region of 
1 England. Eligibility criteria included age 20-65 years, type 2 diabetes diagnosed within the 2 previous six years, body-mass index (BMI) $27-45 \mathrm{~kg} / \mathrm{m}^{2}$, and most recent $\mathrm{HbA} 1 \mathrm{c}>48 \mathrm{mmol} / \mathrm{mol}$ 3 (6.5\%) (or $>43 \mathrm{mmol} / \mathrm{mol}(6.1 \%)$ if taking diabetes medication). Between July 2014 and Aug 4 2016, 298 participants were randomised equally to control (usual care) and intervention 5 groups. Both groups continued to receive optimal routine care under current clinical guidelines.

6 Participants in the intervention arm followed the Counterweight-Plus weight management 7 programme, to achieve and maintain substantial weight loss, aiming for $>15 \mathrm{~kg}$ weight loss. 8 The programme, delivered in the primary care setting by trained dietitians or practice nurses, 9 contained three phases: 'total diet replacement' during which participants consumed only a low energy formula diet (soups and shakes, 825-853 kcal/day) for 12 weeks, which could be extended up to 20 weeks to accommodate holidays or other periods of slow progress, followed by a structured food reintroduction phase of 2-8 weeks, and then longer-term weight loss maintenance. Following weight loss, 'rescue packages' of the formula diet may be provided if $>2 \mathrm{~kg}$ weight was regained or diabetes returned. All oral anti-diabetes and antihypertensive medications were ceased, on safety grounds, when participants began the programme. These were reintroduced under standard protocols following national clinical guidelines, where indicated by regular monitoring of blood glucose and blood pressure. Otherwise, participants in both groups continued to receive diabetes care under current national guidelines and standards. At one year, DiRECT showed remission of diabetes ( $\mathrm{HbA} 1 \mathrm{c}<48 \mathrm{mmol} / \mathrm{mol}(6.5 \%))$ was achieved in $46 \%$ of intervention and $4 \%$ of control participants $(p<0.0001)$ [15]. We have previously briefly reported the intervention cost and cost per diabetes remission [16] and now report the methods used in detail, especially the Counterweight-Plus programme cost elements, and the complete results of the one-year within-trial cost-effectiveness analysis.

\section{Methods}

This analysis adopted the perspective of the UK National Health Service (NHS). Cost per additional diabetes remission at one year (2016/2017 prices) is calculated from the resource use and the proportion of diabetic remissions observed from the Counterweight-Plus and usual-care arms in DiRECT, based on the intention to treat (ITT) principle.

\section{DiRECT intervention set-up cost}

Fixed costs of providing the Counterweight-Plus intervention include 'set-up' costs for training practitioners (nurse or dietitian). Each practitioner received structured training by experienced 
1 Counterweight-Plus research dietitians. This totalled 16 hours of face-to-face sessions (one

2 initial eight-hour session plus one four-hour session for weight loss maintenance and a further

3 four-hour consolidation session). Training is required for one practitioner per participating

4 practice, though several practitioners may undergo training in groups. Costs associated with

5 the training included practitioners' attendance time and instructors' costs, based on a $£ 300$

6 Counterweight-Plus fee (paid per practitioner), that also includes provision of dedicated

7 training materials, and annual licence fee which covers Counterweight-Plus programme

8 support and access to a medical advisor. After training practitioners, Counterweight-Plus research dietitians provide mentoring support for them when they see their first few intervention participants, with standard competency checks and fidelity testing. This service is included in the $£ 300$ Counterweight-Plus fee.

We costed practitioner time using standard UK unit cost sources (Personal Social Service Research Unit (PSSRU)). Training costs were annualised, assuming each trained practitioner remains in place for five years.

\section{DIRECT intervention running cost}

Resource use for running the Counterweight-Plus weight management intervention included the formula diet (total diet replacement sachets), review appointments with a practitioner, and supporting workbooks. The number of sachets issued to each participant and duration of each appointment were collected prospectively throughout the study.

Sachets of low energy formula-diet (reconstituted with water as soups and shakes, 4 sachets daily) are designed to supply all essential micronutrients. Sachets were intended to replace all food during total diet replacement. During the food reintroduction phase, food-based diet gradually replaced the low energy sachets. Occasional further use of sachets, however, was permitted during the weight loss maintenance stage. Participants attended fortnightly review appointments during total diet replacement and food reintroduction stages, and monthly appointments during weight loss maintenance. Actual consumption of sachets and attendances for healthcare appointments were included in the cost analysis; these varied across participants, depending, for example, on adherence, holidays, time to weight loss, and need for 'rescue plans'. The workbooks were provided to participants at the start of each of the phases but were included in full in the cost analysis for each enrolled participant irrespective of potential drop-out [14]. Details of the programme have been described elsewhere $[14,15]$. 
2 Data on all contacts with medical professionals in primary and secondary care were obtained

3 directly from the GP practice records. This ensured the completeness and accuracy of the resource use data, including for those who ceased to engage with the intervention. This method did not depend on self-reporting, and thus avoiding recall bias. Each primary or community care record was indicated as being related to diabetes or otherwise. Unit costs for health care resource use, including medical contacts and hospitalisations, were obtained from published national sources (PSSRU, NHS reference costs, or Information Services Division (ISD) Scotland) for the 2016-2017 financial year (Appendix 1).

Use of oral anti-diabetes and antihypertensive medicines was suspended on initiation of the programme and reinstated as necessary according to NHS clinical guidelines, however, people who achieve and sustain remission, may continue without these medications. Use of these medications was costed according to individual participants' medication records in each participating GP practice. Data included dose, frequency, start and end dates of each medication. Prescriptions for all concomitant medications (i.e., other than the oral antidiabetes and antihypertensive medications) were compared between arms but were not included in our cost estimates. Unit cost for individual doses of each medication was calculated based on the British National Formulary online database (accessed June 2018).

\section{Statistical analysis}

Statistical analysis was conducted according to the intention to treat (ITT) principle with all randomised participants included in the analysis. Patient characteristics have been previously reported elsewhere [15]. Resource use data were incomplete for one participant in each arm $(<1 \%)$ due to relocation. For the one relocated participant in the control arm, we assumed that she/he continued oral anti-diabetes or antihypertensive drugs throughout the period. The relocated intervention group participant attended only one intervention visit, so we also assumed continued usage in that case. We assigned each of these participants zero healthcare contacts. Mean cost was calculated by averaging the aggregated resource use costs (Counterweight-Plus intervention, primary and secondary care, oral anti-diabetes and antihypertensive medication) over all participants within each group. Standard errors of all analyses were adjusted for clustering at GP practice level. An incremental cost effectiveness ratio was calculated as the difference in the groups' total costs divided by the difference in diabetes remission rates at one-year. 95\% confidence intervals were based on 1,000 nonparametric bootstrap iterations (samples with replacement from the observed data). All analyses were undertaken in STATA/MP 14.2 (StataCorp, TX, USA). 


\section{Results}

2

3

4

5

6

7

8

\section{Intervention cost}

The total cost per intervention participant of delivering the Counterweight-Plus programme was $£ 1,137$ (95\% Cl: $£ 1,071, £ 1,205)$ (Table 1). The mean duration of total diet replacement, food reintroduction and weight loss maintenance was 3.5, 2.3 and 3.5 months respectively, including all participants who ceased the intervention. Each participant consumed a mean of 3.6, 0.9 and 0.5 sachets per day and attended 2.2, 1.6 and 1.2 appointments per month for total diet replacement, food reintroduction and weight loss maintenance respectively (Figure 1). In total, each participant was issued a mean of 495 sachets (costed at £708), which accounted for over half of total intervention costs. A total of $15.6(95 \% \mathrm{Cl}: 14.7,16.5)$ practitioner visits (costed at £362) were observed over the first year, and these accounted for approximately one third of total intervention costs.

\section{Routine resource use and cost over one-year}

Table 2 shows the healthcare contacts of participants over the 12-month period. There was little difference between the arms, as might be expected, though participants in the intervention arm had fewer GP visits related to diabetes (mean difference $0.5 ; 95 \% \mathrm{Cl}: 0.2,0.7$ ), and fewer practice nurse visits unrelated to diabetes $(0.5 ; 95 \% \mathrm{Cl}: 0.1,1.0)$. The aggregate number of days using individual oral anti-diabetes and antihypertensive drugs, however, differed greatly between arms with the intervention arm having a total of 332 fewer days per participant on oral anti-diabetes medications and 240 fewer days on antihypertensive drugs.

Table 3 applies unit costs to the resource use. Overall, the intervention group's costs for routine healthcare contacts were $£ 155$ (95\% Cl: $-£ 74$, £394) lower than the control group's. Statistically significant mean differences were observed for oral anti-diabetes drugs of $£ 120$ (95\% Cl: $£ 78, £ 163)$ per participant, and for antihypertensive drugs of $£ 14$ (95\% Cl: $£ 7.9, £ 22)$. Aggregating the intervention costs and routine resource use costs together, the difference in total costs over one-year between the groups was therefore due almost entirely to the intervention delivery cost, with some offset provided through medication cost savings.

\section{Cost-effectiveness for remission of diabetes}

Over the one-year period, the mean cost per participant was $£ 1,827$ (95\% Cl $£ 1,652, £ 2,021)$ in the intervention group and $£ 846(95 \% \mathrm{Cl} £ 685, £ 1,038)$ in the control group (Table 4), leading to an incremental cost difference of $£ 982$ (95\% Cl $£ 732, £ 1,258)$ per participant. 
1 Combined with the incremental remission rate (42\%; 95\% Cl 33\%, 50\%), the incremental cost

2 per diabetes remission over the first year was $£ 2,359$ (95\% Cl £1,668, £3,250).

\section{Discussion}

4 We have analysed the observed resource use over one year, under the DiRECT trial 5 conditions, to estimate the DIRECT/Counterweight-Plus intervention cost and its cost6 effectiveness (incremental cost per remission achieved). The average cost of intervention 7 delivery was $£ 1,137$ per participant randomised to the intervention arm. There were observed 8 reductions in several routine (non-intervention) cost elements such that the net intervention cost per participant was $£ 982$. The intervention delivery costs may be reduced when rolled out in routine practice. For example, the training costs per participant, with an average of five participants per practice in the trial (33 practitioners managing 149 participants), will be lower as each trained practitioner will manage many more people. Lower costs of formula diet sachets per participant in the programme would be expected in routine practice if lower unit costs could be negotiated for large contracts. As patients following the Counterweight-Plus programme do not require normal food during total diet replacement, and less than usual during the food re-introduction and maintenance stages, there will be some decreased spend for patients. A case might be made to introduce out-of-pocket payment for the formula diet sachets. This could apply after a specific period, be part payment, or for ongoing use such as rescue plans or for one sachet per day for weight loss maintenance. For people in some socioeconomic groups there may be value in exploring means tested payments to avoid widening the inequality gap in this area of care. Such options would need careful consideration and ongoing audit to ensure no impact on effectiveness.

The delivery cost of the DiRECT/Counterweight-Plus programme compares favourably with other diabetes remission interventions. There are no directly comparable studies of weight management with diabetes remission as the primary outcome. The US Look AHEAD trial in type 2 diabetes involved an exercise training and weight loss intervention which cost almost twice as much the DiRECT intervention (USD \$2,865 per participant, 2012 value), but DiRECT achieved greater weight losses and a four-fold greater remission rate at 1 year (DiRECT $46 \%$ vs. Look AHEAD 12\%) [17,18]. Bariatric surgery usually produces much greater weight losses and remissions of type 2 diabetes, however, surgery carries risks of mild to serious long-term complications, with frequent vitamin and mineral deficiencies and symptoms such as hypoglycaemia and hypovolemic dumping, and it is expensive (e.g., at £6,346 [19] for laparoscopic gastric bypass, $£ 7,224$ (€8,105 [20]) for vertical banded gastroplasty), with most costs incurred during the initial hospitalisation [21]. 
1 Limited offsetting cost-savings were observed in the initial 12-months (including significantly

2 lower prescription costs). The benefits from weight loss and remission may persist into future 3 years during which the relatively high initial intervention costs do not apply. The two-year 4 analysis will inform this. The numbers of participants prescribed any concomitant medication 5 during the study (i.e., excluding oral anti-diabetes, diuretic and antihypertensive drugs) were comparable between the arms. Given this, the low cost of most items, and the likelihood that any aggregate differences would tend to favour the intervention arm through the broader benefits related to weight loss, we excluded the concomitant medications from the present analysis. However the proportion of participants taking no prescription drugs increased in the intervention arm at 12 months in DiRECT [15], pointing to further possible cost advantages for the intervention in the longer term.

\section{Strengths and Limitations}

This analysis is based on one-year outcomes, and detailed data collection, during a rigorously conducted randomised trial. DiRECT was the first study in a primary care setting to set remission of type 2 diabetes as a primary outcome. The intervention was well received by participants, with significantly improved quality of life at one year, and healthcare contacts outside the trial were reduced (e.g. GP visits as shown in the results). The participants were very typical of people currently living with type 2 diabetes, up to 6 years after diagnosis. A high proportion were from socially deprived circumstances, where type 2 diabetes is most prevalent and difficult to manage [22]. The study design ensured that cost and outcome data were available from primary care records in nearly all the participants (296/298 for costs and 298/298 for remission rates) for ITT analysis, even if they had ceased to engage with the programme. The control group received standard treatment under guidelines which are broadly similar internationally. Our results are thus likely to be robust and generalizable.

The costs of the intervention, and of routine care, are similar in many other studies [23,24]. For example, the standard care arm among people with prediabetes in the UK Let's Prevent trial had an annual mean non-inpatient health service cost of $£ 437$ and medication cost of $£ 124$ [24], which is similar to the control arm resource use in our study ( $£ 520$ for non-inpatient health care services, and $£ 168$ for primary medications as shown in Table 3 ). As such the present economic analysis is likely to be widely transferable to diabetes care elsewhere, at least within countries with similar healthcare systems. However, the population studied was almost entirely European, and up to six years after diagnosis: we cannot be certain whether the results are applicable to people from other racial or ethnic origins where type 2 diabetes has different characteristics, or with diabetes for over six years. Asian populations have a 
1 higher prevalence of diabetes than their European counterparts for the same BMI [25]. Also,

2 many Asian people with diabetes develop both early $\beta$ cell dysfunction and insulin resistance,

3 so many require earlier insulin treatment [26]. There is therefore need for research to evaluate

4 intensive weight management in Asian populations and to develop appropriate methods for

5 developing countries, where type 2 diabetes and its treatment costs are rising dramatically.

\section{$6 \quad$ Future long-term cost-effectiveness analysis}

7 Over a period of one year, it would be unrealistic to expect to identify resource savings relating 8 to the long-term consequences of diabetes, such as neuropathy, renal failure and vison loss, 9 and DiRECT was not powered for these outcomes. Nevertheless, given the clear benefit of lower $\mathrm{HbA} 1 \mathrm{c}$ in reducing complications [27], diabetes remission rates such as those seen in DiRECT at one-year are potentially transformative both for participants' health, quality of life, and longevity, and for the burden to healthcare systems such as the NHS. Participants' abilities to maintain weight loss and healthy lifestyles, and avoid reversion to a diabetic state will be critical but are under-researched, and will require appropriate research and development investment for programme improvement. There is ample evidence that substantial weight loss and a period of remission consistently improves multiple cardiometabolic risk factors [28,29], and that weight management interventions may extend life expectancy [12]. On-going follow up in DiRECT will contribute to modelling of long-term health gains, resource savings following initial remission, and inform long-term cost-effectiveness modelling and healthcare planning. Recent studies using different methodologies have indicated reduced life expectancy with type 2 diabetes of 6 - 7 years for those who are diagnosed with diabetes at the age of 50 years (similar to DiRECT population) [7,30,31]. Irrespective of future resource use that may be avoided, such estimates imply costs per quality-adjusted life-year (QALY) ratios comfortably within the cost-effectiveness threshold of $£ 20,000$ - $£ 30,000$ per QALY gained applied to healthcare interventions in the UK.

\section{Conclusions}

Providing the DiRECT/Counterweight-Plus intervention in primary care incurs a cost lower than the average annual direct cost of managing a person with type 2 diabetes (including complications at later stage), and has the potential for long-term cost effectiveness, based on the data up to one year. The programme involves early intervention costs that may generate substantial future healthcare resource savings if remissions and reduced drug prescriptions are maintained by sufficient numbers of participants. DiRECT is on-going, and further data will support future cost-effectiveness analyses incorporating long-term outcomes including qualityadjusted life-years. However, given the likelihood that a period of remission will reduce 
1 disabling long-term diabetes complications, as well as improving quality of life, the case 2 already appears strong for shifting resources within diabetes care budgets to offer the support 3 for people with diabetes to attempt remission. 


\section{References}

1 Ogurtsova K, da Rocha Fernandes JD, Huang Y, Linnenkamp U, Guariguata L, Cho NH et al. IDF Diabetes Atlas: Global estimates for the prevalence of diabetes for 2015 and 2040. Diabetes Res Clin Pract 2017;128:40-50.

2 American Diabetes Association. Economic Costs of Diabetes in the U.S. in 2017. Diabetes Care 2018;41:917-28.

3 Hex N, Bartlett C, Wright D, Taylor M, Varley D. Estimating the current and future costs of Type 1 and Type 2 diabetes in the UK, including direct health costs and indirect societal and productivity costs. Diabet Med 2012;29:855-62.

$4 \quad$ Ulrich S, Holle R, Wacker M, Stark R, Icks A, Thorand B et al. Cost burden of type 2 diabetes in Germany: results from the population-based KORA studies. BMJ Open 2016;6:e012527.

$5 \quad$ Unnikrishnan R, Shah VN, Mohan V. Challenges in diagnosis and management of diabetes in the young. Clin Diabetes Endocrinol 2016;2:18.

6 Zhuo X, Zhang P, Barker L, Albright A, Thompson TJ, Gregg E. The Lifetime Cost of Diabetes and Its Implications for Diabetes Prevention. Diabetes Care 2014;37:2557.

7 Rao Kondapally Seshasai S, Kaptoge S, Thompson A, Di Angelantonio E, Gao P, Sarwar N et al. Diabetes mellitus, fasting glucose, and risk of cause-specific death. N Engl J Med 2011;364:829-41.

$8 \quad$ Dixon JB, O'Brien PE, Playfair J, Chapman L, Schachter LM, Skinner S et al. Adjustable gastric banding and conventional therapy for type 2 diabetes: a randomized controlled trial. Jama 2008;299:316-23.

9 Welburn RS, Findlay I, Sareela A, Somers S, Mahawar KobotNDCaWPKRDCS. The United Kingdom Bariatric Registry of the British Obesity and Metabolic Surgery Society (2nd Registry Report). 2014.

10 Wharton S, Serodio KJ, Kuk JL, Sivapalan N, Craik A, Aarts MA. Interest, views and perceived barriers to bariatric surgery in patients with morbid obesity. Clin Obes 2016;6:154-60.

11 Lim EL, Hollingsworth KG, Aribisala BS, Chen MJ, Mathers JC, Taylor R. Reversal of type 2 diabetes: normalisation of beta cell function in association with decreased pancreas and liver triacylglycerol. Diabetologia 2011;54:2506-14.

12 Lean ME, Powrie JK, Anderson AS, Garthwaite PH. Obesity, weight loss and prognosis in type 2 diabetes. Diabet Med 1990;7:228-33.

13 Wing RR, Lang W, Wadden TA, Safford M, Knowler WC, Bertoni AG et al. Benefits of modest weight loss in improving cardiovascular risk factors in overweight and obese individuals with type 2 diabetes. Diabetes Care 2011;34:1481-6.

14 Leslie WS, Ford I, Sattar N, Hollingsworth KG, Adamson A, Sniehotta FF et al. The Diabetes Remission Clinical Trial (DiRECT): protocol for a cluster randomised trial. BMC Family Practice 2016;17:20.

15 Lean ME, Leslie WS, Barnes AC, Brosnahan N, Thom G, McCombie L et al. Primary care-led weight management for remission of type 2 diabetes (DiRECT): an open-label, cluster-randomised trial. Lancet 2018;391:541-51.

16 Xin Y, Davies A, McCombie L, Briggs A, Messow CM, Grieve E et al. Within-trial cost and 1-year costeffectiveness of the DiRECT/Counterweight-Plus weight-management programme to achieve remission of type 2 diabetes. Lancet Diabetes Endocrinol 2019;7:169-72.

17 Gregg EW, Chen H, Wagenknecht LE, Clark JM, Delahanty LM, Bantle J et al. Association of an intensive lifestyle intervention with remission of type 2 diabetes. Jama 2012;308:2489-96.

18 Rushing J, Wing R, Wadden TA, Knowler WC, Lawlor M, Evans M et al. Cost of intervention delivery in a lifestyle weight loss trial in type 2 diabetes: results from the Look AHEAD clinical trial. Obes Sci Pract 2017;3:15-24.

19 Ackroyd R, Mouiel J, Chevallier JM, Daoud F. Cost-effectiveness and budget impact of obesity surgery in patients with type-2 diabetes in three European countries. Obes Surg 2006;16:1488-503.

20 van Mastrigt GA, van Dielen FM, Severens JL, Voss GB, Greve JW. One-year cost-effectiveness of surgical treatment of morbid obesity: vertical banded gastroplasty versus Lap-Band. Obes Surg 2006;16:75-84.

21 Picot J, Jones J, Colquitt JL, Gospodarevskaya E, Loveman E, Baxter L et al. The clinical effectiveness and cost-effectiveness of bariatric (weight loss) surgery for obesity: a systematic review and economic evaluation. Health Technol Assess 2009;13:1-190, 215-357, iii-iv.

22 Taylor R, Leslie WS, Barnes AC, Brosnahan N, Thom G, McCombie L et al. Clinical and metabolic features of the randomised controlled Diabetes Remission Clinical Trial (DiRECT) cohort. Diabetologia 2018;61:589-98.

23 Laxy M, Wilson ECF, Boothby CE, Griffin SJ. Incremental Costs and Cost Effectiveness of Intensive Treatment in Individuals with Type 2 Diabetes Detected by Screening in the ADDITION-UK Trial: An Update with Empirical Trial-Based Cost Data. Value Health 2017;20:1288-98.

24 Leal J, Ahrabian D, Davies MJ, Gray LJ, Khunti K, Yates T et al. Cost-effectiveness of a pragmatic structured education intervention for the prevention of type 2 diabetes: economic evaluation of data from the Let's Prevent Diabetes cluster-randomised controlled trial. BMJ Open 2017;7:e013592.

25 Yoon $\mathrm{KH}$, Lee JH, Kim JW, Cho JH, Choi YH, Ko SH et al. Epidemic obesity and type 2 diabetes in Asia. Lancet 2006;368:1681-8.

26 Ma RC, Chan JC. Type 2 diabetes in East Asians: similarities and differences with populations in Europe and the United States. Ann N Y Acad Sci 2013;1281:64-91. 
27 UK Prospective Diabetes Study (UKPDS) Group. Intensive blood-glucose control with sulphonylureas or insulin compared with conventional treatment and risk of complications in patients with type 2 diabetes (UKPDS 33). UK Prospective Diabetes Study (UKPDS) Group. Lancet 1998;352:837-53.

28 Sjostrom L, Lindroos AK, Peltonen M, Torgerson J, Bouchard C, Carlsson B et al. Lifestyle, diabetes, and cardiovascular risk factors 10 years after bariatric surgery. N Engl J Med 2004;351:2683-93.

29 Brethauer SA, Aminian A, Romero-Talamas H, Batayyah E, Mackey J, Kennedy L et al. Can diabetes be surgically cured? Long-term metabolic effects of bariatric surgery in obese patients with type 2 diabetes mellitus. Ann Surg 2013;258:628-36; discussion 36-7.

$30 \quad$ Nwaneri C, Bowen-Jones D, Cooper H, Chikkaveerappa K, Afolabi BA. Falling mortality rates in Type 2 diabetes mellitus in the Wirral Peninsula: a longitudinal and retrospective cohort population-based study. Postgrad Med J 2012;88:679.

$31 \quad$ Loukine L, Waters C, Choi BCK, Ellison J. Impact of diabetes mellitus on life expectancy and healthadjusted life expectancy in Canada. Popul Health Metr 2012;10:7. 


\section{Tables and figures}

Table 1 Intervention resource use components and cost (per participant) ( $n=149)$ over the first 12 months of the DiRECT trial

\begin{tabular}{|c|c|c|c|c|c|c|}
\hline Intervention cost components & & & & & & Total \\
\hline 1a. Intervention set-up cost & \multicolumn{2}{|c|}{ Units } & \multicolumn{2}{|c|}{ Unit cost } & & \\
\hline $\begin{array}{l}\text { Counterweight-Plus specialist training, support } \\
\text { and mentoring }\end{array}$ & \multicolumn{2}{|c|}{33 practitioners } & \multicolumn{2}{|c|}{$£ 300$ per practitioner } & & $£ 9,900$ \\
\hline Practice nurses and dieticians' time & \multicolumn{2}{|c|}{16 hours per practitioner } & \multicolumn{2}{|c|}{$£ 42$ per hour ${ }^{\mathrm{c}}$} & & $£ 22,176$ \\
\hline Total set-up cost & & & & & & $£ 32,076$ \\
\hline Total set-up cost annualised over five years a & & & & & & $£ 7,104$ \\
\hline \multicolumn{3}{|l|}{ Total intervention set-up cost per participant } & & & & $£ \underline{48^{e}}$ \\
\hline $\begin{array}{l}\text { 1b. Intervention running resource use and costs } \\
\text { at each stage of the Counterweight-Plus } \\
\text { programme }\end{array}$ & $\begin{array}{l}\text { Total diet } \\
\text { replacement }\end{array}$ & $\begin{array}{l}\text { Food } \\
\text { reintroduction }\end{array}$ & $\begin{array}{c}\text { Weight } \\
\text { Maintenance }\end{array}$ & $\begin{array}{l}\text { Rescue } \\
\text { package - } \\
\text { Total diet } \\
\text { replacement }\end{array}$ & $\begin{array}{l}\text { Rescue } \\
\text { package - } \\
\text { food } \\
\text { reintroduction }\end{array}$ & Total $(95 \% \mathrm{Cl})$ \\
\hline Intervention running resource use & \multicolumn{5}{|c|}{ Mean (SD) $\left(n=149^{b}\right)$} & \\
\hline Number of practice nurse or dietician visits & $7.7(2.9)$ & $3.7(1.9)$ & $3.5(2.7)$ & $0.3(0.7)$ & $0.4(1.0)$ & $15.6(14.7,16.5)$ \\
\hline Number of Counterweight-Plus sachets issued & $383(156)$ & $62(50)$ & $30(48)$ & $10(27)$ & $10(31)$ & $495(461,530)$ \\
\hline Intervention running cost & \multicolumn{5}{|c|}{ Mean (SD) $\left(n=149^{b}\right)(£)$} & \\
\hline Practice nurse/dietitian visits ${ }^{c}$ & $172(63)$ & $88(47)$ & $84(63)$ & $7.7(19)$ & $10(24)$ & $£ 362(337,384)$ \\
\hline Sachets ${ }^{c}$ & $547(223)$ & $89(71)$ & $42(68)$ & $14(39)$ & $15(44)$ & $£ 708(659,757)$ \\
\hline Counterweight-Plus booklets & & & & & & $£ 20(-)$ \\
\hline Total intervention running cost per participant & & & & & & $£ \underline{1,089(1,023,1,158)}$ \\
\hline
\end{tabular}

Total cost per participant $(n=149)$

a. Annualising the total cost over five years using the formula, equivalent annual cost $(E):=K /\left[\left(1-1 /(1+r)^{n}\right) / r\right]$. $K=£ 32,076, r=3.5 \%, n=5$, gives an annual specialist training and support cost of £48 per participant.

b. Includes six randomised participants who did not initiate the intervention.

c. Unit cost £42/hour was obtained from the PSSRU unit cost of medical and social care 2016/2017; sachet costs £20 per 14 sachets.

d. $95 \% \mathrm{Cl}$ was obtained from 1000 iterations of bootstrap.

e. This is the training cost for 33 practitioners managing 149 participants (a ratio of $1: 4.5$ ), as implemented in the trial. 
Table 2 NHS resource use quantity per participant 12 months trial period

\begin{tabular}{|c|c|c|c|}
\hline \multirow[b]{2}{*}{ Resource use items a } & \multicolumn{2}{|c|}{ Mean (SD) } & \multirow{2}{*}{$\begin{array}{l}\text { Mean difference } \\
\left(95 \% \mathrm{Cl}^{\mathrm{c}}\right)\end{array}$} \\
\hline & $\begin{array}{c}\text { Intervention } \\
\left(\mathrm{n}=149^{\mathrm{b}}\right)\end{array}$ & $\begin{array}{c}\text { Control } \\
\left(n=149^{b}\right)\end{array}$ & \\
\hline \multicolumn{4}{|c|}{$\begin{array}{l}\text { Primary and community care visits related to } \\
\text { diabetes }\end{array}$} \\
\hline GP & $0.44(0.82)$ & $0.89(1.24)$ & $-0.45(-0.69,-0.20)$ \\
\hline Practice nurse & $1.73(1.41)$ & $2.03(1.52)$ & $-0.30(-0.64,0.03)$ \\
\hline Health care assistant & $0.26(0.64)$ & $0.32(0.72)$ & $-0.07(-0.23,0.09)$ \\
\hline Community care & $0.41(0.67)$ & $0.43(0.87)$ & $-0.02(-0.21,0.15)$ \\
\hline \multicolumn{4}{|c|}{ Primary care visits not related to diabetes } \\
\hline GP & $3.91(4.71)$ & $4.05(4.70)$ & $-0.14(-1.24,0.95)$ \\
\hline Practice nurse & $0.94(1.53)$ & $1.46(2.74)$ & $-0.52(-1.03,-0.07)$ \\
\hline Health care assistant & $0.16(0.48)$ & $0.28(1.54)$ & $-0.11(-0.41,0.09)$ \\
\hline Community care & $0.28(0.90)$ & $0.28(1.75)$ & $-0.00(-0.38,0.27)$ \\
\hline Outpatient visits & $1.31(1.90)$ & $1.81(2.72)$ & $-0.50(-1.02,0.03)$ \\
\hline Hospitalisation length of stay (day) & $0.21(0.98)$ & $0.17(0.72)$ & $0.03(-0.16,0.24)$ \\
\hline \multicolumn{4}{|c|}{ Medication days (sum of individual drug days) ${ }^{d}$} \\
\hline Oral anti-diabetes drugs & $104(197)$ & $436(312)$ & $-332(-397,-267)$ \\
\hline Antihypertensive drugs & $148(218)$ & 387 (389) & $-240(-314,-166)$ \\
\hline
\end{tabular}

a. The resource use included all the health care contacts the participants had over the one-year period except for the intervention visits, including the routine annual checks for diabetes such as retina screening for both arms.

b. Included one participant in each arm who moved away from the trial participating practice. Their healthcare resource use was assumed to be 0 after they moved away, and their medication use was assumed to continue since they moved away.

c. $95 \% \mathrm{Cl}$ for the mean differences were obtained from bootstrap.

d. The number of 'individual-drug-days' was generated by adding together the number of days on each individual drug taken by participants during the one-year period. If the participant has more than one oral anti-diabetes medication administered during the one-year period, then the days were added up together, even when the drugs have overlapping period. 
Table 3 NHS cost $(£)$ per participant ( $n=149$ for each arm) over the 12 months trial period

\begin{tabular}{|c|c|c|c|}
\hline \multirow[b]{2}{*}{ Cost (per participant) } & \multicolumn{2}{|c|}{ Mean cost (SD) $(£)$} & \multirow{2}{*}{$\begin{array}{c}\text { Mean difference } \\
\text { (Intervention - } \\
\text { Control) }(£)\left(95 \% \mathrm{Cl}^{\mathrm{b}}\right)\end{array}$} \\
\hline & $\begin{array}{c}\text { Intervention } \\
\left(\mathrm{n}=149^{\mathrm{a}}\right)\end{array}$ & $\begin{array}{c}\text { Control } \\
\left(n=149^{a}\right)\end{array}$ & \\
\hline \multicolumn{4}{|l|}{ 3a. Resource use of health care contacts } \\
\hline \multicolumn{4}{|l|}{$\begin{array}{l}\text { Primary and community care visits related to } \\
\text { diabetes }\end{array}$} \\
\hline GP & $17(31)$ & $34(47)$ & $-17(-26,-7.6)$ \\
\hline Practice nurse & $19(15)$ & $22(16)$ & $-3.3(-7.0,0.3)$ \\
\hline Health care assistant & $1.0(2.6)$ & $1.3(2.9)$ & $-0.3(-0.9,0.4)$ \\
\hline Community care & $16(28)$ & $18(43)$ & $-2.2(-11,5.6)$ \\
\hline \multicolumn{4}{|l|}{$\begin{array}{l}\text { Primary and community care visits not related } \\
\text { to diabetes }\end{array}$} \\
\hline GP & $149(179)$ & $154(178)$ & $-5.4(-47,36)$ \\
\hline Practice nurse & $10(17)$ & $16(30)$ & $-5.6(-11,-0.8)$ \\
\hline Health care assistant & $0.6(1.9)$ & $1.1(6.2)$ & $-0.5(-1.6,0.4)$ \\
\hline Community care & $13(45)$ & $13(92)$ & $-0.2(-20,14)$ \\
\hline Outpatient visits & $244(476)$ & $261(407)$ & $-17(-111,83)$ \\
\hline Hospitalisation & $187(796)$ & $157(713)$ & $30(-142,201)$ \\
\hline $\begin{array}{l}\text { Total cost of resource use of health care } \\
\text { contacts }\end{array}$ & $\underline{656(1,047)}$ & $\underline{677(1,028)}$ & $-21(-249,215)$ \\
\hline \multicolumn{4}{|l|}{ 3b. Medications } \\
\hline Anti-diabetes drugs & $29(86)$ & $149(228)$ & $-120(-163,-78)$ \\
\hline Antihypertensive drugs & $5.3(9.1)$ & $19(43)$ & $-14(-22,-7.9)$ \\
\hline $\begin{array}{l}\text { Total cost of oral anti-diabetes and } \\
\text { antihypertensive drugs }\end{array}$ & $\underline{34(87)}$ & $\underline{168(229)}$ & $-134(-177,-93)$ \\
\hline $\begin{array}{l}\text { Total cost of resource use (incl. } \\
\text { medications, regardless of relation to } \\
\text { diabetes) }\end{array}$ & $691(1,058)$ & $846(1,066)$ & $-155(-394,74)$ \\
\hline \multicolumn{4}{|l|}{ 3c. Intervention cost } \\
\hline$\underline{\text { Total intervention cost (see Table 1) }}$ & $\underline{1,137(421)}$ & $\underline{0(-)}$ & $\underline{1,137(1,071,1,205)}$ \\
\hline GRAND TOTAL cost per participant & $1,827(1,145)$ & $846(1,066)$ & $982(732,1,258)$ \\
\hline
\end{tabular}

a. Included one participant in each arm who moved away from the trial participating practice. Their healthcare resource use was assumed to be 0 after they moved away, and their medication use was assumed to continue since they moved away.

b. $95 \% \mathrm{Cl}$ values for the mean differences were obtained from the 1,000 iteration bootstrap. 
Table 4 Cost-effectiveness results of DiRECT intervention over 1 year within trial time horizon

\begin{tabular}{lcc}
\hline & Diabetes Remission (\%) $\left(95 \% \mathrm{Cl}^{\mathrm{a}}\right)$ & Mean cost $(£)\left(95 \% \mathrm{Cl}^{\mathrm{a}}\right)$ \\
\hline Intervention & $45.6(37.9,53.6)$ & $1,827(1,652,2,021)$ \\
Control & $4.0(1.3,7.5)$ & $846(685,1,038)$ \\
$\begin{array}{l}\text { Difference } \\
\text { Cost per diabetes } \\
\text { remission (95\% Cl) }\end{array}$ & $41.6(33.0,50.4)$ & $982(732,1,258)$ \\
\hline
\end{tabular}

a. the $95 \% \mathrm{Cl}$ for the incremental cost and incremental number of remissions were both obtained from the 1,000 iteration bootstrap. 
a. Number of sachets per day

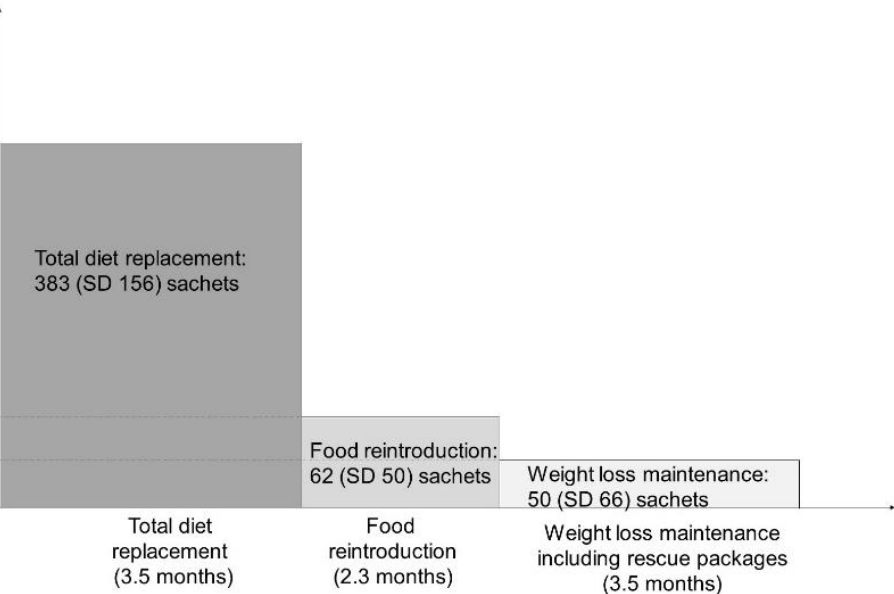

b. Number of appointments per month

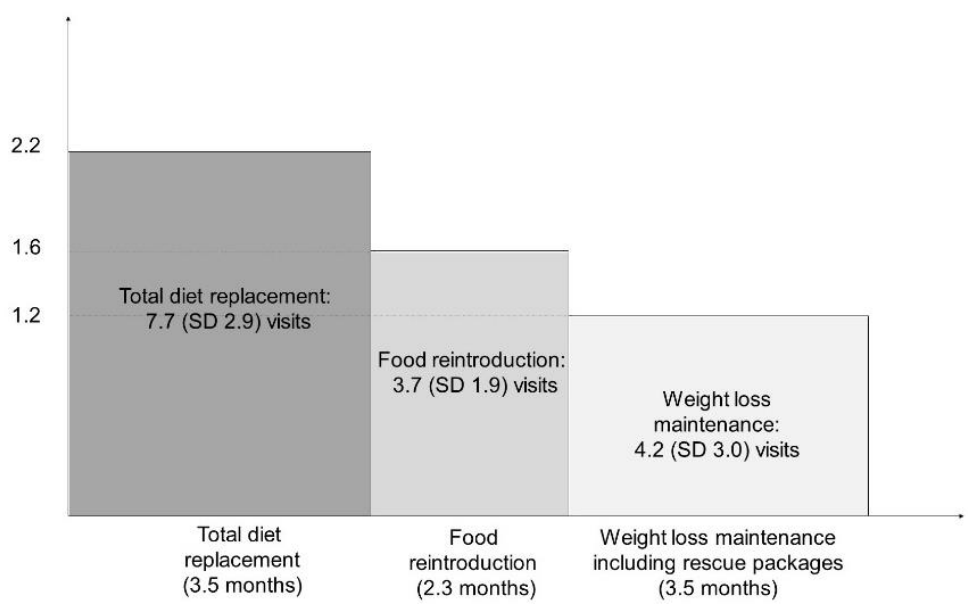

Figure 1 Mean number of sachets (a) and mean number of appointments per month (b) offered to participants during each stage of the DiRECT intervention within year $1(n=149$, including the participants who discontinued from the trial). 


\section{Appendix 1 Unit costs for community and outpatient health- care resource use}

\begin{tabular}{|c|c|c|}
\hline $\begin{array}{l}\text { Resource use item } \\
\text { (unit used in the } \\
\text { source) }\end{array}$ & Unit Cost & Source \\
\hline \multicolumn{3}{|c|}{ NHS community based resource use } \\
\hline $\begin{array}{l}\text { GP } \\
\text { (per contact) }\end{array}$ & $£ 38.00$ & $\begin{array}{l}\text { PSSRU } 2016 / 17 \text { pg. } 162 \text {. Per patient contact lasting } 9 \cdot 22 \\
\text { minutes, with qualifications }\end{array}$ \\
\hline $\begin{array}{l}\text { Practice Nurse (per } \\
\text { hour) }\end{array}$ & $\begin{array}{c}£ 42 \cdot 00 \\
\text { ( } £ 10 \cdot 85 \text { per contact) }\end{array}$ & $\begin{array}{l}\text { PSSRU 2016/17 pg. } 160 \text {. Nursing average cost per hour, } \\
\text { with qualifications. } \\
\text { Duration of contact per patient is } 15 \cdot 5 \text { minutes (PSSRU } \\
2014 / 15 \text {, pg.174, based on the } 2006 / 07 \text { UK general practice } \\
\text { survey) }\end{array}$ \\
\hline $\begin{array}{l}\text { Healthcare assistant } \\
\text { (per hour) }\end{array}$ & $\begin{array}{c}£ 24 \\
(£ 4 \text { per contact) }\end{array}$ & $\begin{array}{l}\text { PSSRU 2016/17 pg.159. Nurses Band 3. Average duration } \\
\text { per contact is estimated to be } 10 \mathrm{~min} \text {. }\end{array}$ \\
\hline $\begin{array}{l}\text { Podiatrist } \\
\text { (per contact) }\end{array}$ & $£ 41$ & $\begin{array}{l}\text { NHS reference cost - Community health services - } \\
\text { Podiatrist Tier 1, General podiatry P09A. }\end{array}$ \\
\hline $\begin{array}{l}\text { Pharmacist } \\
\text { (per hour) }\end{array}$ & $\begin{array}{c}£ 43 \\
\text { ( } £ 10.75 \text { per contact) }\end{array}$ & $\begin{array}{l}\text { PSSRU } 2016 / 17 \mathrm{pg} .153-155 \text {. Community Scientific and } \\
\text { professional staff Pharmacist Band } 6 \text {. Length of contact } \\
\text { assumed to be } 15 \mathrm{~min} \text {. }\end{array}$ \\
\hline $\begin{array}{l}\text { Dietitians (per } \\
\text { contact) }\end{array}$ & f85 & $\begin{array}{l}\text { NHS reference cost } 2016 / 17 \text { community health service.A03 } \\
\text { dietitian } f 85 \text { per contact. }\end{array}$ \\
\hline $\begin{array}{l}\text { Physiotherapist } \\
\text { (per contact) }\end{array}$ & $f 53$ & $\begin{array}{l}\text { NHS reference cost, AHP allied health professionals A08A1, } \\
\text { physiotherapist, adult, one to one. }\end{array}$ \\
\hline $\begin{array}{l}\text { Clinical } \\
\text { psychologist/counsel } \\
\text { lor } \\
\text { (per hour) }\end{array}$ & $f 53$ & $\begin{array}{l}\text { PSSRU 2016/17 pg. 153-155. Community Scientific and } \\
\text { professional staff band } 7 \text { ( } ₫ 53 \text { per hour) clinical } \\
\text { psychologist/counsellor. Length per contact assumed to be } \\
1 \mathrm{hr} .\end{array}$ \\
\hline $\begin{array}{l}\text { Occupational } \\
\text { therapist } \\
\text { (per contact) }\end{array}$ & $f 77$ & $\begin{array}{l}\text { NHS reference cost community health service. Occupational } \\
\text { therapist, adult, one to one. }\end{array}$ \\
\hline $\begin{array}{l}\text { District nurse } \\
\text { (per visit) }\end{array}$ & f37 & $\begin{array}{l}\text { NHS reference cost - community health services. N02AF } \\
\text { District Nurse, Adult, Face to face. }\end{array}$ \\
\hline Haemodialysis & f137.03 & $\begin{array}{l}\text { NHS reference cost 2016/17 Satellite Haemodialysis or } \\
\text { Filtration, with Access via Haemodialysis Catheter, } 19 \text { years } \\
\text { and over }\end{array}$ \\
\hline \multicolumn{3}{|l|}{ A\&E services } \\
\hline $\begin{array}{l}\text { Urgent and } \\
\text { emergency Calls } \\
\text { answered (NHS 111, } \\
\text { or 999) }\end{array}$ & f7 & $\begin{array}{l}\text { NHS Reference costs } 2016 / 17 \text { highlights, analysis and } \\
\text { introduction to the data. Table } 6 \text {. Costs by currency for } \\
\text { ambulance services between } 2014 / 15 \text { and 2016/17. Unit } \\
\text { cost for calls. (pg.9) }\end{array}$ \\
\hline $\begin{array}{l}\text { Hear and treat or } \\
\text { refer (ambulance } \\
\text { trust clinician } \\
\text { resolves the call or }\end{array}$ & f37 & $\begin{array}{l}\text { NHS Reference costs } 2016 / 17 \text { highlights, analysis and } \\
\text { introduction to the data. Table 6. Costs by currency for } \\
\text { ambulance services between 2014/15 and 2016/17. Unit } \\
\text { cost for hear and treat or refer. (pg.9) }\end{array}$ \\
\hline
\end{tabular}




\begin{tabular}{|c|c|c|}
\hline $\begin{array}{l}\text { refer over the } \\
\text { phone) }\end{array}$ & & \\
\hline $\begin{array}{l}\text { Ambulance service } \\
\text { (see and treat or } \\
\text { refer) }\end{array}$ & f181 & $\begin{array}{l}\text { NHS Reference costs } 2016 / 17 \text { highlights, analysis and } \\
\text { introduction to the data. Table 6. Costs by currency for } \\
\text { ambulance services between } 2014 / 15 \text { and 2016/17. Unit } \\
\text { cost for see and treat or refer. (pg.9) }\end{array}$ \\
\hline $\begin{array}{l}\text { Ambulance (see and } \\
\text { treat and convey) }\end{array}$ & $£ 248$ & $\begin{array}{l}\text { NHS Reference costs 2016/17 highlights, analysis and } \\
\text { introduction to the data. Table 6. Costs by currency for } \\
\text { ambulance services between 2014/15 and 2016/17. Unit } \\
\text { cost for see and treat and convey (pg.9) }\end{array}$ \\
\hline $\begin{array}{l}\text { A\&E attendance } \\
\text { (per attendance) }\end{array}$ & f148 & $\begin{array}{l}\text { NHS Reference costs } 2016 / 17 \text { highlights, analysis and } \\
\text { introduction to the data. Table } 2 \text {. Unit costs by point of } \\
\text { delivery, 2014/15 and 2016/17 (f). Unit cost for A\&E } \\
\text { attendance (pg.5) }\end{array}$ \\
\hline \multicolumn{3}{|c|}{$\begin{array}{l}\text { Outpatient appointment by specialty } \\
\text { (per attendance) }\end{array}$} \\
\hline $\begin{array}{l}\text { Average outpatient } \\
\text { appointment cost }\end{array}$ & f168 & $\begin{array}{l}\text { ISD Scotland } 2016 / 17 \text { Outpatients specialty cost. R044X- } \\
\text { outpatient consultant clinics, by specialty, by board. Net } \\
\text { cost per attendance }\end{array}$ \\
\hline Gynaecology & $£ 169$ & $\begin{array}{l}\text { ISD Scotland } 2016 / 17 \text { Outpatients specialty cost. R044X- } \\
\text { outpatient consultant clinics, by specialty, by board. Net } \\
\text { cost per attendance }^{c}\end{array}$ \\
\hline $\begin{array}{l}\text { Gynaecology (nurse } \\
\text { led) }\end{array}$ & f58 & $\begin{array}{l}\text { ISD Scotland } 2016 / 17 \text { Outpatients specialty cost. R044X- } \\
\text { outpatient consultant clinics, by specialty, by board. Net } \\
\text { cost per attendance }\end{array}$ \\
\hline Gastroenterology & $f 226$ & $\begin{array}{l}\text { ISD Scotland } 2016 / 17 \text { Outpatients specialty cost. R044X- } \\
\text { outpatient consultant clinics, by specialty, by board. Net } \\
\text { cost per attendance }\end{array}$ \\
\hline $\begin{array}{l}\text { Gastroenterology } \\
\text { (nurse led) }\end{array}$ & f134 & $\begin{array}{l}\text { ISD Scotland } 2016 / 17 \text { Outpatients specialty cost. R044X- } \\
\text { outpatient consultant clinics, by specialty, by board. Net } \\
\text { cost per attendance }\end{array}$ \\
\hline Cardiology & $£ 143$ & $\begin{array}{l}\text { ISD Scotland } 2016 / 17 \text { Outpatients specialty cost. R044X- } \\
\text { outpatient consultant clinics, by specialty, by board. Net } \\
\text { cost per attendance }\end{array}$ \\
\hline Dermatology & $£ 157$ & $\begin{array}{l}\text { ISD Scotland } 2016 / 17 \text { Outpatients specialty cost. R044X- } \\
\text { outpatient consultant clinics, by specialty, by board. Net } \\
\text { cost per attendance }\end{array}$ \\
\hline Geriatric assessment & $£ 190$ & $\begin{array}{l}\text { ISD Scotland } 2016 / 17 \text { Outpatients specialty cost. R044X- } \\
\text { outpatient consultant clinics, by specialty, by board. Net } \\
\text { cost per attendance }\end{array}$ \\
\hline $\begin{array}{l}\text { Ear, Nose \& Throat } \\
\text { (ENT) }\end{array}$ & £114 & $\begin{array}{l}\text { ISD Scotland } 2016 / 17 \text { Outpatients specialty cost. R044X- } \\
\text { outpatient consultant clinics, by specialty, by board. Net } \\
\text { cost per attendance }{ }^{c}\end{array}$ \\
\hline Ophthalmology & £154 & $\begin{array}{l}\text { ISD Scotland } 2016 / 17 \text { Outpatients specialty cost. R044X- } \\
\text { outpatient consultant clinics, by specialty, by board. Net } \\
\text { cost per attendance }\end{array}$ \\
\hline $\begin{array}{l}\text { Ophthalmology } \\
\text { (nurse led) }\end{array}$ & $f 76$ & $\begin{array}{l}\text { ISD Scotland } 2016 / 17 \text { Outpatients specialty cost. R044X- } \\
\text { outpatient consultant clinics, by specialty, by board. Net } \\
\text { cost per attendance }\end{array}$ \\
\hline General medicine & $£ 255$ & $\begin{array}{l}\text { ISD Scotland } 2016 / 17 \text { Outpatients specialty cost. R044X- } \\
\text { outpatient consultant clinics, by specialty, by board. Net } \\
\text { cost per attendance }\end{array}$ \\
\hline
\end{tabular}




\begin{tabular}{|c|c|c|}
\hline $\begin{array}{l}\text { General surgery } \\
\text { (excluding vascular } \\
\text { surgery) }\end{array}$ & $£ 147$ & $\begin{array}{l}\text { ISD Scotland } 2016 / 17 \text { Outpatients specialty cost. R044X- } \\
\text { outpatient consultant clinics, by specialty, by board. Net } \\
\text { cost per attendance }\end{array}$ \\
\hline Clinical genetics & f553 & $\begin{array}{l}\text { ISD Scotland } 2016 / 17 \text { Outpatients specialty cost. RO44X- } \\
\text { outpatient consultant clinics, by specialty, by board. Net } \\
\text { cost per attendance }\end{array}$ \\
\hline Haematology & $£ 370$ & $\begin{array}{l}\text { ISD Scotland 2016/17 Outpatients specialty cost. R044X- } \\
\text { outpatient consultant clinics, by specialty, by board. Net } \\
\text { cost per attendance }{ }^{c}\end{array}$ \\
\hline General psychiatry & $£ 233$ & $\begin{array}{l}\text { ISD Scotland } 2016 / 17 \text { Outpatients specialty cost. R044X- } \\
\text { outpatient consultant clinics, by specialty, by board. Net } \\
\text { cost per attendance }\end{array}$ \\
\hline Orthopaedic & f119 & $\begin{array}{l}\text { ISD Scotland 2016/17 Outpatients specialty cost. R044X- } \\
\text { outpatient consultant clinics, by specialty, by board. Net } \\
\text { cost per attendance }\end{array}$ \\
\hline Neurology & $f 214$ & $\begin{array}{l}\text { ISD Scotland 2016/17 Outpatients specialty cost. R044X- } \\
\text { outpatient consultant clinics, by specialty, by board. Net } \\
\text { cost per attendance }\end{array}$ \\
\hline Neurosurgery & f149 & $\begin{array}{l}\text { ISD Scotland } 2016 / 17 \text { Outpatients specialty cost. R044X- } \\
\text { outpatient consultant clinics, by specialty, by board. Net } \\
\text { cost per attendance }\end{array}$ \\
\hline Obstetrics & f181 & $\begin{array}{l}\text { ISD Scotland } 2016 / 17 \text { Outpatients specialty cost. RO44X- } \\
\text { outpatient consultant clinics, by specialty, by board. Net } \\
\text { cost per attendance }\end{array}$ \\
\hline Clinical oncology & $£ 250$ & $\begin{array}{l}\text { ISD Scotland 2016/17 Outpatients specialty cost. R044X- } \\
\text { outpatient consultant clinics, by specialty, by board. Net } \\
\text { cost per attendance }\end{array}$ \\
\hline $\begin{array}{l}\text { Oral surgery \& } \\
\text { medicine }\end{array}$ & f111 & $\begin{array}{l}\text { ISD Scotland 2016/17 Outpatients specialty cost. R044X- } \\
\text { outpatient consultant clinics, by specialty, by board. Net } \\
\text { cost per attendance }\end{array}$ \\
\hline Pain relief & $£ 203$ & $\begin{array}{l}\text { ISD Scotland 2016/17 Outpatients specialty cost. R044X- } \\
\text { outpatient consultant clinics, by specialty, by board. Net } \\
\text { cost per attendance }\end{array}$ \\
\hline Respiratory medicine & $£ 199$ & $\begin{array}{l}\text { ISD Scotland } 2016 / 17 \text { Outpatients specialty cost. RO44X- } \\
\text { outpatient consultant clinics, by specialty, by board. Net } \\
\text { cost per attendance }\end{array}$ \\
\hline Rheumatology & $£ 214$ & $\begin{array}{l}\text { ISD Scotland 2016/17 Outpatients specialty cost. R044X- } \\
\text { outpatient consultant clinics, by specialty, by board. Net } \\
\text { cost per attendance }\end{array}$ \\
\hline Urology & f154 & $\begin{array}{l}\text { ISD Scotland } 2016 / 17 \text { Outpatients specialty cost. R044X- } \\
\text { outpatient consultant clinics, by specialty, by board. Net } \\
\text { cost per attendance }{ }^{c}\end{array}$ \\
\hline Vascular surgery & f154 & $\begin{array}{l}\text { ISD Scotland } 2016 / 17 \text { Outpatients specialty cost. RO44X- } \\
\text { outpatient consultant clinics, by specialty, by board. Net } \\
\text { cost per attendance }\end{array}$ \\
\hline Radiology & £65.59 & $\begin{array}{l}\text { ISD Scotland 2016/17 R120 Radiology services. Outpatients } \\
\text { specialty cost. R044X - outpatient consultant clinics, by } \\
\text { specialty, by board. Net cost per attendance }{ }^{\text {c }}\end{array}$ \\
\hline Midwife service & f80.98 & $\begin{array}{l}\text { NHS reference cost 2016/17. Total outpatient attendances } \\
560 \text { midwifery service. }\end{array}$ \\
\hline Clinical microbiology & f119.40 & $\begin{array}{l}\text { NHS reference cost 2016/17. Total outpatient attendances } \\
322 \text { clinical microbiology. }\end{array}$ \\
\hline
\end{tabular}




\begin{tabular}{|c|c|c|}
\hline Endocrinology & $\begin{array}{c}\text { £158.34 (average) } \\
£ 161.83 \text { (consultant led) } \\
£ 110.60 \text { (non consultant } \\
\text { led) }\end{array}$ & $\begin{array}{l}\text { NHS reference cost 2016/17. Total outpatient attendances } \\
302 \text { endocrinology. }\end{array}$ \\
\hline Podiatry & f46.64 & $\begin{array}{l}\text { NHS reference cost 2016/17. Total outpatient attendances } \\
653 \text { podiatry. }\end{array}$ \\
\hline Clinical immunology & $£ 263.67$ & $\begin{array}{l}\text { NHS reference cost 2016/17. Total outpatient attendances } \\
316 \text { Clinical immunology. }\end{array}$ \\
\hline Orthotics & $£ 119 \cdot 07$ & $\begin{array}{l}\text { NHS reference cost } 2016 / 17 \text {. Total outpatient attendances. } \\
658 \text { Orthotics }\end{array}$ \\
\hline Physiotherapy & $£ 48 \cdot 81$ & $\begin{array}{l}\text { NHS reference cost } 2016 / 17 \text {. Total outpatient attendances. } \\
650 \text { physiotherapy }\end{array}$ \\
\hline $\begin{array}{l}\text { Out of hours GP } \\
\text { service } \\
\text { (per contact) }\end{array}$ & $f 71 \cdot 07^{a}$ & $\begin{array}{l}\text { National Audit Office. Out of Hours GP Services in England. } \\
\text { London: Department of Health and NHS England; } 2014 \\
\text { (https://www.nao.org.uk/wp- } \\
\text { content/uploads/2014/09/Out-of-hours-GP-services-in- } \\
\text { England1.pdf) pg 15-16. a national average cost, for opted- } \\
\text { out services of } £ 68.30 \text { in 2013-14. }\end{array}$ \\
\hline $\begin{array}{l}\text { Out of hours NHS } \\
\text { telephone service }\end{array}$ & $£ 37 \cdot 00$ & NHS reference cost (hear and treat or refer) \\
\hline $\begin{array}{l}\text { Diabetic retina } \\
\text { screening }\end{array}$ & $£ 37 \cdot 14^{b}$ & Scanlon PH et al. $2009 / 10$ NHS reference cost - $£ 33$ \\
\hline Walk in services & $f 41.64^{b}$ & $\begin{array}{l}\text { PSSRU 2009/10 pg. } 119 \text { A\&E SERVICES (Weighted average } \\
\text { of attendances) - walk in services leading to admitted (not } \\
\text { admitted) } £ 37(37)\end{array}$ \\
\hline \multicolumn{3}{|l|}{ Diagnostic services } \\
\hline $\begin{array}{l}\text { Other radiology } \\
\text { (includes } \\
\text { 'conventional' X } \\
\text { rays) }\end{array}$ & $f 72 \cdot 83^{b}$ & $\begin{array}{l}\text { ISD Scotland } 2009 / 2010 . \text { R120X radiology services by board. } \\
\text { Other radiology (includes 'conventional' X rays) net cost per } \\
\text { examination: } f 64 \cdot 71\end{array}$ \\
\hline Ultrasonic & $£ 57 \cdot 40^{b}$ & $\begin{array}{l}\text { ISD Scotland } 2009 / 2010 \text {. R120X radiology services by board. } \\
\text { Ultrasonic net cost per examination: } £ 51.00\end{array}$ \\
\hline $\begin{array}{l}\text { Magnetic Resonance } \\
\text { Imaging }\end{array}$ & $f 243 \cdot 55^{b}$ & $\begin{array}{l}\text { ISD Scotland 2009/2010. R120X radiology services by board. } \\
\text { Magnetic Resonance Imaging, net cost per examination: } \\
£ 216.40\end{array}$ \\
\hline CT scan & $f 124 \cdot 35^{b}$ & $\begin{array}{l}\text { ISD Scotland } 2009 / 2010 \text {. R120X radiology services by board. } \\
\text { CT scan net cost per examination: } £ 110 \cdot 49\end{array}$ \\
\hline $\begin{array}{l}\text { ECG } \\
\text { (electrocardiogram } \\
\text { monitoring) }\end{array}$ & f52 & $\begin{array}{l}\text { NHS reference cost 2016/17 Directly accessed diagnostic } \\
\text { services. EY51Z Electrocardiogram monitoring or stress } \\
\text { testing. }\end{array}$ \\
\hline
\end{tabular}

a. HCHS inflation factor 1.04062 (2013/14 Pay and prices index (PPI) 290.5 / 2016/17 PPI 302.3)

b. HCHS inflation factor 1.12547 (2009/10 Pay and prices index (PPI) 268.6 / 2016/17 PPI 302.3)

c. ISD R044X cost notes: these costs are mainly for consultation or very minor procedures, but may include patients who receive more complex (and expensive) treatments.

References for unit costs:

1 Curtis L, Burns A. Unit Costs of Health and Social Care 2017, Personal Social Services Research Unit, University of Kent, Canterbury. 2017. https://www.pssru.ac.uk/project-pages/unitcosts/unit-costs-2017/ (accessed 3 Aug 2018). 
2 Improvement N. National Health Service Reference Costs. 2017.

https://improvement.nhs.uk/resources/reference-costs/ (accessed 3 Aug 2018).

3 ISD Scotland. Specialty Costs. 2018. http://www.isdscotland.org/Health-

Topics/Finance/Costbook/Speciality-Costs/ (accessed 1 June 2018).

$4 \quad$ National institute for Health and Care Excellence. BNF British National Formulary - NICE.

2018. https://bnf.nice.org.uk/ (accessed 19 September 2018).

5 Information Centre. 2006/07 UK general practice workload survey, Primary Care Statistics, Information Centre, Leeds. 2007.

6 Scanlon PH, Aldington SJ, Leal J, et al. Development of a cost-effectiveness model for optimisation of the screening interval in diabetic retinopathy screening. Chapter 8, Phase 4: costeffectiveness of differing screening intervals in diabetic retinopathy screening. Health Technol Assess 2015; 19(74): 1-116. 